\title{
Attitudes towards neurology among medical undergraduates
}

\author{
Anna Pokryszko-Dragan ${ }^{1}$, John Mottershead ${ }^{2}$, Gill Aitken ${ }^{3}$ \\ ${ }^{1}$ Department of Neurology, Wroclaw Medical University, Wroclaw, Poland \\ ${ }^{2}$ Department of Neurology, Dunedin Public Hospital, Dunedin, New Zealand \\ ${ }^{3}$ Clinical Education Programme, University of Edinburgh, United Kingdom
}

\section{ABSTRACT}

Diseases of the nervous system are an important contributor to clinical and social problems. Therefore there is a need to provide undergraduates and postgraduates of medical faculties with adequate training in neurology. However, many shortcomings have been observed in this field, often associated with students' negative perception of neurology. The aim of this study was to explore attitudes towards neurology amongst undergraduates of the medical faculty at Wroclaw Medical University, and the reasons for these attitudes. As a qualitative component of the study, a focus group discussion was conducted with six fifth year undergraduates. The findings of the focus group and a literature search informed the content of a questionnaire distributed among fifth year students of the medical faculty, including non-Poles attending English Division. The responses to the closed questions were analysed quantitatively and subjected to statistical analysis while the free text comments were analysed qualitatively. Triangulation of the findings from the focus group and the survey was performed. 134 Polish students and 75 English-speaking ones responded to the survey. The majority of participants perceived neurology to be interesting and important for medical education, and it was highly ranked as a potential future speciality. The majority of the survey respondents regarded neurology as difficult and mentioned specific drawbacks. In spite of similar general perceptions of neurology, Polish and English-speaking students differed in their perceptions of particular aspects, conditioned by diversity in cultural backgrounds and earlier experiences associated with neurology. The course in neurology affected attitudes towards the subject more than preceding experiences, mostly in a positive manner. The fifth year medical undergraduates expressed mostly positive attitudes towards neurology. Cultural background and the course in neurology were the main factors contributing to attitudes in these students.

Key words: neurology, undergraduates, attitudes, neurophobia

(Neurol Neurochir Pol 2019; 53 (1): 61-73)

\section{Introduction}

Diseases of the nervous system affect $30 \%$ of the population, with increasing morbidity associated with the ageing of societies, and these diseases constitute a significant clinical and social problem [1]. Therefore there is a clear need to educate competent neurologists and other specialists with appropriate knowledge in this field [1]. In the 1990s, the phenomenon of a fear of neurology was identified among medical students and named 'neurophobia' [2]. Despite progress in neurology and in methods of teaching, there is evidence from medical faculties [3-5] that 'neurophobia' remains a phenomenon. This may be associated with the diversity of healthcare settings, teaching resources and professionals involved in teaching neurology [6].

In the Polish literature there is limited evidence for this problem [7-8]. Undergraduate training in neurology in Poland is obligatory, follows official guidelines, and is provided by specialists. In recent years, no shortage of trained neurologists has been documented in Poland [9]. However, in informal discussions, teachers often complain about their students' reluctance to learn neurology, and neurologists complain about other specialists' poor competence in the basics of neurology. Therefore, undergraduate attitudes towards neurology seemed worthy of investigation in Poland. 
In recent years, a growing diversity of medical students has been noted: English Divisions (the same curriculum taught in English) have developed at the majority of Polish medical faculties and the number of their non-Polish attendees is constantly increasing. A smaller group of non-Polish students also temporarily attends courses at medical faculties within the international exchange programme (the European Community Action Scheme for the Mobility of University Students - ERASMUS). These undergraduates may hold diverse attitudes towards particular specialities, including neurology, conditioned by the prevailing opinions in their countries of origin.

The aim of this study was to explore attitudes towards neurology among medical undergraduates and the background to these attitudes, including the impact of the course in neurology.

\section{Material and methods}

The participants in this study were fifth year students of the medical faculty at Wroclaw Medical University, who had completed the basic part of the neurology course (during their first semester) and were currently attending its second part (towards the end of the second semester). Fifth year students were selected because they shared the same status and experience and were available as respondents due to their obligatory participation in the neurology course.

Mixed qualitative and quantitative methods were used, mainly in a sequential manner. Qualitative methods were used to explore problems and quantitative methods were used to quantify and analyse data in a larger sample of participants. We integrated these two methods in a further stage of the study, with triangulation of findings from both components. Initially, a thorough literature review was conducted to formulate topics for discussion in the focus group and for an initial version of the questionnaire. The focus group was set up to allow students the opportunity to discuss their experiences and to support the formulation of the final version of the questionnaire. Further quantitative and qualitative findings were obtained from the survey.

To avoid any pressure arising from the teacher-student relationship, and to encourage honesty and interactivity of discussion, the focus group was moderated by a student. A senior (sixth year) student was chosen, who had already passed the exam in neurology and had displayed a special interest both in neurology and educational issues during activity in the Students' Scientific Club. The idea of the focus group and the research topic had been discussed with this senior student prior to obtaining her consent to moderate the discussion. Participants for the focus group were recruited through the website of students' societies. The invitation was addressed to all fifth year students, equally encouraging those engaged or not in any additional educational activity and those interested in neurology or those who had already decided on another speciality. Potential participants could contact the researcher or the moderator for more information. Nine students initially considered participation, with six eventually participating.

There was one meeting of the focus group that lasted for approximately two hours. At the beginning, the participants were given a list of 28 expressions (based on a relevant literature search) and asked to choose the five expressions that they most associated with neurology. At the end they were asked to review the initial version of the questionnaire and to comment on it. Their discussion was recorded and the transcript of the recording was analysed to enable the identification of particular themes. Subsequently, the moderator (and the willing participants) were asked to review the description of findings, and to provide feedback.

The questionnaire contained closed and open-ended items. The closed ones were either dichotomous (yes/no) or Likert-type format with five answers (including a neutral response), with easily completed tick-boxes. The initial version of the questionnaire was based on an extensive literature search and the combined experiences of the authors. Then it was piloted by several sixth year students (who had already completed the neurology course) and reviewed by several junior assistants in neurology (who still remembered the students' perspective but were already involved in teaching). Finally, the questionnaire was presented to the participants of the focus group for comment.

A paper version of the questionnaire (Polish and English versions for particular students' groups) was chosen for easier dissemination. The questionnaires were offered to the students before the onset of their classes and collected afterwards at the exit door, in order to maximise confidentiality and anonymity.

The data from the closed items were subjected to statistical analysis. The number of responses was calculated and their distribution was compared between genders and Polish/non-Polish participants, using the Chi-square test with Yate's correction. $\mathrm{P} \leq 0.01$ was considered statistically significant, because of the multiple comparisons performed. The analysis was performed using EPIINFO software (Version 7.1.1.14, 2013).

For ethical reasons, special attention was paid within the design of the study to minimise pressure from hierarchical teacher-student relationships and to assure anonymity and confidentiality of data. The Bioethical Board of Wroclaw Medical University approved the project. Informed consent was obtained from all the subjects prior to their participation in the focus group or prior to responding to the questionnaire. The information contained an explanation of the aim and conduct of the study and assurances that participation would not affect the subjects' further participation in their degree or any form of assessment, and that the results would not be revealed or published before the end of the exam session. The informed consent forms were stored - for confidentiality reasons - separately from the transcripts of discussions and completed questionnaires. 


\section{Results}

\section{The focus group}

The six participants in the focus group were fifth year students: three men and three women, aged 23-25 (mean 23.7). The moderator was a sixth year female student.

\section{Attitudes towards neurology}

\section{General and specific aspects of neurology}

From the list of expressions associated with neurology that we provided, the participants most often selected: 'logical', 'making progress' and 'interesting' (from the descriptive terms) and 'detailed examination', 'cognitive dysfunction', and 'chronic diseases' (from the related items) (Tab. 1).

The students mostly perceived neurology to be an interesting subject, with the diagnostic process based on logical thinking and supported by technology-based tools. They noted recent progress in terms of early recognition of the diseases and - to a lesser extent - within therapy. Still unsolved problems in neurology were regarded as scope for future investigation (Tab. 2).

Objections to neurology were associated with the type of disorders handled: their insidious onset or subtle signs hindering diagnosis, frequent speech or cognitive impairment resulting in communication problems, chronic course and adverse prognosis with still few treatment options available, with resultant frustration and emotional load for the physician (Tab. 2).

\section{Neurology as future speciality}

Three students considered neurology as their future career while the other three planned to pursue other specialities. The latter considered basic competence in neurology as necessary in their future work.

A neurologist's inpatient practice was perceived as interesting but demanding, with numerous consultations, including emergencies. The opportunity to deal with outpatients in an independent establishment was also appreciated for its greater stability and higher income. The prestige of being a neurologist was perceived as being underestimated by the public but valued by the patients who were treated. The following qualities were regarded as necessary for a good neurologist: calmness, accuracy, observation and reasoning skills, empathy, patience and an ability to maintain an emotional distance. Those planning to become neurologists were aware of the discussed drawbacks and challenges of this speciality, but felt ready to face them.

\section{Factors affecting attitudes towards neurology}

\section{Demographics}

Female students were anxious about problems with work-life balance and possible gender discrimination during training in neurology. However, the latter was attributed to the hierarchical structure of healthcare settings rather than to the speciality itself. Male students did not express concern in this field. There were no other gender-specific comments or statements from the focus group participants.

Table 1. Expressions associated with neurology chosen by the focus group participants

\begin{tabular}{|c|c|c|c|}
\hline Expression & Number of choices & Expression & Number of choices \\
\hline logical & 7 & detailed examination & 3 \\
\hline making progress & 4 & cognitive dysfunction & 3 \\
\hline interesting & 3 & chronic diseases & 2 \\
\hline useful & 2 & rare disorders & 1 \\
\hline difficult & 2 & neuroimaging & 1 \\
\hline conservative & 1 & consultations & 1 \\
\hline timid & 1 & rehabilitation & 1 \\
\hline stressful & 1 & symptomatic treatment & 1 \\
\hline emotional load & 1 & disability & 0 \\
\hline complicated & 0 & emergency conditions & 0 \\
\hline effective & 0 & topographic diagnostics & 0 \\
\hline easy & 0 & electrophysiological studies & 0 \\
\hline up-to-date & 0 & & \\
\hline palliative & 0 & & \\
\hline boring & 0 & & \\
\hline niche & 0 & & \\
\hline
\end{tabular}


Table 2. Perceptions of positive and negative aspects of neurology

\section{A: Positive}

St.1: it's like an intriguing puzzle - you put together findings from history and examination, think logically - and work out the solution

St.4: neurology is necessary in so many fields - when you deal with contusions, congenital failures, systemic diseases..

St.2: there has been much progress in diagnostic methods - one can recognise the disease earlier (..), especially neuroimaging is very helpful (..), you may have a real insight into the brain

St. 5: with advanced technology, there are also more treatment options available

St. 3: there is still a lot to discover - the background and nature of disorders - a perfect area for research

B: Positive

Interesting (functions of the brain, specificity of the nervous system).

Variety of problems and disorders.

Based on logical thinking.

Recent progress in diagnostics and treatment.

Challenging.

Scope for research (many unknown issues to explore).

Various opportunities of job (ENG).

Narrow speciality - easy to become an expert (ENG).

\section{A: Negative}

St. 5: it's so stressful: you may overlook something important - the neurological signs seem so explicit in the textbook, but not at all in real patients

St.6: searching for the diagnosis is great - but then you should tell it to the patient (...) and often there is not much more to offer

St. 1: I find it difficult to talk to the patients with aphasia or dementia. (...) It's such an emotional burden - these chronic and disabling diseases think it may lead to burn-out syndrome

St.4: when you still meet similar patients - with stroke or headache - it's not so challenging any more

\section{B: Negative}

Difficult: many complex issues, vast material for a narrow speciality.

Theory hardly applicable in practice (PL).

Type of diseases: mostly chronic, progressive and disabling, with poor outcomes.

Specific patients: elderly, difficult to communicate with.

Too few treatment options, lack of effective procedures.

Frustrating, emotional burden.

Little availability of residency posts (PL).

Few opportunities for interesting jobs (PL).

A: by the focus group participants, B: by respondents to the survey.

\section{Experiences preceding neurology course}

The participants' earlier experiences related to neurology included meeting patients with neurological disorders during other clinical classes (emergency unit, internal diseases) or in their private lives, the opinions of other specialists (both positive and negative), and information acquired from the media.

\section{The neurology course}

The courses in neurosciences (preclinical years) and neurology formed the main source of the students' opinion about neurology. The former highlighted specificity and uniqueness of neurosciences, while the latter revealed clinical aspects of neurology and their usefulness in other specialities.

\section{The survey}

\section{Respondents}

290 Polish and 110 English versions of the questionnaire were handed out. The survey was responded to by 134 Polish students (PL) and 75 English speaking ones (ENG), with response rates of $46.2 \%$ and $68.2 \%$ respectively.

PL and ENG did not differ in gender (c. 40\% men, $60 \%$ women). Mean age was slightly lower in ENG (23.7 vs 24.2; $\mathrm{p}=0.008)$.

Among ENG, 22 were participants in ERASMUS and 53 were students of English Division. English was the native language for 14 persons (from Canada, USA, Ireland, and
Sudan), while the remaining 61 came from Sweden (25), Italy (11), Germany (10), Spain (4), Ukraine (4), Portugal (2), Saudi Arabia (2), Slovenia (1) and Switzerland (1).

All the respondents answered the closed questions completely; $97.7 \%$ of PL and $90.7 \%$ of ENG provided free text comments invited by open questions.

\section{Attitudes towards neurology}

\section{General perception of neurology}

In both groups the majority of respondents regarded neurology as "somewhat" or "definitely" difficult, interesting and important for general medical education. A moderate proportion of respondents found it not relevant for their future speciality or remained undecided (Fig. 1 A-D).

\section{Neurology as future speciality}

Twenty four (17.9\%) PL and 14 (18.7\%) ENG would consider neurology as their future speciality, which ranked it among the top five most preferred specialities (Tab. 3).

\section{Specific aspects of neurology}

The majority of respondents agreed with statements concerning the link between neurology and difficult basic neurosciences, progress in neurosciences, specificity of the diagnostic process (based on deductive thinking, perceived as difficult and challenging), and types of disorders (chronic, 


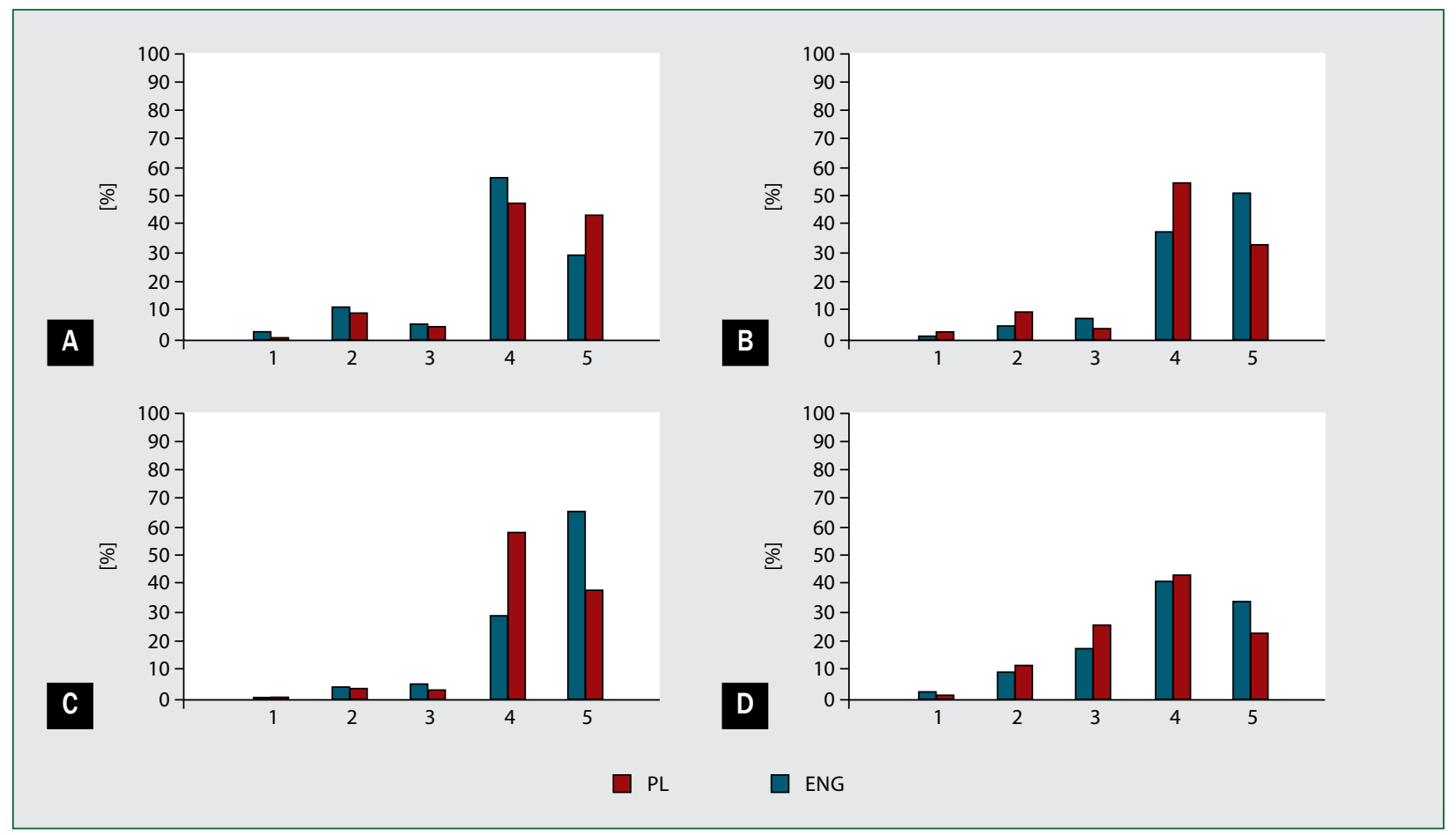

Figure 1. Distribution of responses to question regarding the general perception of neurology: Do you find neurology - A. difficult? B. interesting? C. important for medical education? D. relevant for your future speciality? 1- definitely not, 2- rather not, 3 - don't know, 4 - somewhat yes, 5 - definitely yes, PL- Polish students, ENG - English-speaking students

disabling) (Tab. 4). There was a greater diversity of responses concerning the difficulty of neurological examination, the incurability of neurological disorders, and emergency conditions covered by neurology. A large percentage of respondents expressed no opinion ("don't know") on the following issues: up-to-date diagnostic methods and therapeutic options used in neurology, unknown background and incurability of neurological disorders, and links between neurology and other specialities (Tab. 4).

In the open questions, the respondents were asked to describe briefly the reasons for their preference (or lack of it) for neurology as their future speciality. Among the latter, 29\% PL and 38\% ENG claimed "lack of interest" and "preference for other specialities" as the main reason, while $4.5 \%$ PL and 20\% ENG added some potential aspects in favour of neurology (Tab. 2).

\section{Factors affecting attitudes towards neurology}

\section{Demographics}

Among PL there were no gender differences in responses reflecting attitudes towards neurology.

Among ENG, fewer men than women "definitely" agreed and more "rather" disagreed that neurological diagnostics is difficult and challenging $\left(\chi^{2}=10.9, \mathrm{df}=3, \mathrm{p}=0.012\right)$.
Significant differences were found between PL and ENG in the responses reflecting their attitudes towards neurology (Fig. 1, Tab. 4).

Fewer PL than ENG "definitely" agreed and more "rather" disagreed with recognising neurology to be important for general medical education $\left(\chi^{2}=17.8, \mathrm{df}=3, \mathrm{p}=0.0005\right)$.

More PL than ENG "definitely" agreed that up-to-date diagnostics are used in neurology, that neurological disorders are chronic and have unknown background, and that neurological patients require interdisciplinary care. Fewer PL than ENG "definitely" agreed and more "rather" disagreed that neurology deals with emergency conditions and symptoms secondary to systemic diseases, and may be associated with an emotional burden (Tab. 4).

\section{Experiences preceding neurology course}

The respondents had a range of neurology-related experiences preceding their course in neurology (Fig. 2).

ENG more often than PL had met a specialist or trainee in neurology (56\% vs 37.3\%, p = 0.014), learnt about a neurological problem from professional resources $(86.7 \%$ vs $58.2 \%$, $\mathrm{p}=0.00004)$, and had heard more positive $(22.7 \%$ vs $7.46 \%$, $\mathrm{p}=0.0002)$ and less negative (5.3\% vs $22.4 \%, \mathrm{p}=0.0002)$ opinions about neurology.

No gender differences were found among the respondents within this domain. 
Table 3. Preferences for the future specialty among the respondents to the survey

\begin{tabular}{|c|c|c|c|}
\hline \multicolumn{2}{|c|}{ ENG $(n=75)$} & \multicolumn{2}{|c|}{ PL $(n=134)$} \\
\hline Considered future specialty & $\begin{array}{c}\text { Number (\%) of stu- } \\
\text { dents }\end{array}$ & Considered future specialty & $\begin{array}{c}\text { Number (\%) of stu- } \\
\text { dents }\end{array}$ \\
\hline Gynecology/obstetrics & $18(24 \%)$ & Radiology & $28(20.9 \%)$ \\
\hline Pediatrics & $17(22.7 \%)$ & Pediatrics & $26(19.4 \%)$ \\
\hline Internal diseases & $14(18.7 \%)$ & Internal diseases & $26(19.4 \%)$ \\
\hline Neurology & $14(18.7 \%)$ & Neurology & $24(17.9 \%)$ \\
\hline Cardiology & $13(17.3 \%)$ & Anesthesiology & $24(17.9 \%)$ \\
\hline Dermatology & $13(17.3 \%)$ & Family medicine & $20(14.9 \%)$ \\
\hline Surgery & $13(17.3 \%)$ & Cardiology & $18(13.4 \%)$ \\
\hline Family medicine & $13(17.3 \%)$ & Psychiatry & $18(13.4 \%)$ \\
\hline Infectious diseases & $11(14.7 \%)$ & Gynecology/obstetrics & $13(9.7 \%)$ \\
\hline Anesthesiology & $9(12 \%)$ & Endocrinology & $13(9.7 \%)$ \\
\hline Emergency medicine & $9(12 \%)$ & Oncology & $12(8.9 \%)$ \\
\hline Orthopedics & $6(8 \%)$ & Ophthalmology & $11(8.2 \%)$ \\
\hline Radiology & $5(6.7 \%)$ & Dermatology & $11(8.2 \%)$ \\
\hline Endocrinology & $5(6.7 \%)$ & Infectious diseases & $10(7.5 \%)$ \\
\hline Cardiosurgery & $5(6.7 \%)$ & Surgery & $10(7.5 \%)$ \\
\hline Neurosurgery & $4(5.3 \%)$ & Otolaryngology & $10(7.5 \%)$ \\
\hline Plastic surgery & $4(5.3 \%)$ & Orthopedics & $7(5.2 \%)$ \\
\hline Pediatric surgery & $4(5.3 \%)$ & Emergency medicine & $6(4.5 \%)$ \\
\hline Gastroenterology & $4(5.3 \%)$ & Plastic surgery & $5(3.7 \%)$ \\
\hline Otolaryngology & $4(5.3 \%)$ & Neurosurgery & $4(2.9 \%)$ \\
\hline Ophthalmology & $4(5.3 \%)$ & Urology & $3(2.2 \%)$ \\
\hline Urology & $3(4 \%)$ & Vascular surgery & $2(1.5 \%)$ \\
\hline Psychiatry & $3(4 \%)$ & Nephrology & $2(1.5 \%)$ \\
\hline Nephrology & $2(2.7 \%)$ & Rheumatology & $2(1.5 \%)$ \\
\hline Hematology & $2(2.7 \%)$ & Pathology & $2(1.5 \%)$ \\
\hline Oncology & $2(2.7 \%)$ & Hematology & $1(1.5 \%)$ \\
\hline Forensic medicine & $1(2.7 \%)$ & Gastroenterology & $1(1.5 \%)$ \\
\hline Already chosen specialty & $31(41.3 \%)$ & Already chosen specialty & $54(40.3 \%)$ \\
\hline
\end{tabular}

ENG - English speaking students; PL - Polish students

\section{The neurology course}

An equal percentage of PL and ENG (42.6\%) claimed that they had changed their previous opinion on neurology having experienced the course, and for approximately one third of them (36.6\% PL, 34.7\% ENG), this was influenced by a teacher.

Among those who changed their opinion on neurology, the majority found it more interesting, or even enjoyable, than they had anticipated (three students expressed the opposite view). A more thorough knowledge of the nervous system and better understanding of the links between symptoms and their background made the learning less difficult and stressful. Several students claimed that they had a better overview of neurology (they recognised a wider spectrum of diseases and progress in therapy), realised its relevance for other specialities, and found it less frustrating than they had expected. Four students started to consider neurology as their future career. Teachers mostly influenced these positive attitudes by effective explanation of neurological problems, highlighting practical issues, evoking interest and an encouraging approach. However, a few PL students commented on a teacher's performance, which had discouraged them more than the course itself.

\section{Discussion}

\section{Overview}

A positive response rate to the survey, especially among non-Poles, allowed a representative sample of the fifth year undergraduates' opinion to be obtained. Although the focus 
Table 4. Distribution of responses to the question: "How much do you agree with the statements (concerning various aspects of neurology)" and their comparison between Polish (PL) and English-speaking (ENG) students

\begin{tabular}{|c|c|c|c|c|c|c|c|c|c|}
\hline & & $\begin{array}{l}\text { Definitely } \\
\text { not } \%\end{array}$ & $\begin{array}{l}\text { Rather } \\
\text { not } \%\end{array}$ & $\begin{array}{l}\text { Don't } \\
\text { know } \\
\%\end{array}$ & $\begin{array}{l}\text { Somewhat } \\
\text { yes } \%\end{array}$ & $\begin{array}{l}\text { Defini- } \\
\text { tely yes } \\
\%\end{array}$ & $x^{2}$ & df & $\mathbf{p}$ \\
\hline \multirow{2}{*}{$\begin{array}{l}\text { Learning neurology requires knowledge } \\
\text { of difficult anatomy and physiology of the } \\
\text { nervous system }\end{array}$} & $P L$ & 0 & 4.5 & 1.7 & 46.3 & 47.5 & \multirow[b]{2}{*}{6.80} & \multirow[b]{2}{*}{4} & \multirow[b]{2}{*}{0.15} \\
\hline & ENG & 1.3 & 1.3 & 0 & 38.7 & 58.7 & & & \\
\hline \multirow{2}{*}{$\begin{array}{l}\text { Neurosciences constitute an interesting and } \\
\text { constantly developing knowledge domain }\end{array}$} & $P L$ & 0 & 6 & 6 & 42.5 & 45.5 & \multirow{2}{*}{11.3} & \multirow{2}{*}{3} & \multirow{2}{*}{0.01} \\
\hline & ENG & 0 & 0 & 12 & 28 & 60 & & & \\
\hline \multirow{2}{*}{$\begin{array}{l}\text { Neurological examination is difficult to per- } \\
\text { form and interpret }\end{array}$} & $P L$ & 0.8 & 33.6 & 5.9 & 45.5 & 14.2 & \multirow{2}{*}{4.53} & \multirow{2}{*}{4} & \multirow{2}{*}{0.34} \\
\hline & ENG & 5.3 & 33.3 & 6.7 & 42.7 & 12 & & & \\
\hline \multirow{2}{*}{$\begin{array}{l}\text { Diagnostics of neurological symptoms and } \\
\text { signs is based on rational and deductive } \\
\text { thinking }\end{array}$} & $P L$ & 0 & 6.7 & 11.3 & 44 & 38 & \multirow[b]{2}{*}{0.91} & \multirow[b]{2}{*}{3} & \multirow[b]{2}{*}{0.82} \\
\hline & ENG & 0 & 6.7 & 9.3 & 50.7 & 33.3 & & & \\
\hline \multirow{2}{*}{$\begin{array}{l}\text { Variety of up-to-date diagnostics methods } \\
\text { are used in neurology }\end{array}$} & $P L$ & 0 & 4.5 & 8.9 & 36.6 & 50 & \multirow{2}{*}{10.6} & \multirow{2}{*}{3} & \multirow{2}{*}{0.01} \\
\hline & ENG & 0 & 6.7 & 22.7 & 38.7 & 32 & & & \\
\hline \multirow{2}{*}{$\begin{array}{l}\text { Diagnosis of neurological disorders is often } \\
\text { difficult and challenging }\end{array}$} & $P L$ & 0 & 3.7 & 4.5 & 51.5 & 40.3 & \multirow{2}{*}{2.77} & \multirow{2}{*}{3} & \multirow{2}{*}{0.43} \\
\hline & ENG & 0 & 5.3 & 6.7 & 58.7 & 29.3 & & & \\
\hline \multirow{2}{*}{$\begin{array}{l}\text { The background of neurological diseases } \\
\text { often remains unknown }\end{array}$} & $P L$ & 0 & 7.5 & 7.5 & 45.5 & 39.6 & \multirow{2}{*}{14.6} & \multirow{2}{*}{3} & \multirow{2}{*}{0.002} \\
\hline & ENG & 0 & 6.7 & 22.7 & 50.7 & 20 & & & \\
\hline \multirow[t]{2}{*}{ Neurological diseases are mostly incurable } & $P L$ & 0 & 17.9 & 20.9 & 45.5 & 15.7 & 158 & 3 & 066 \\
\hline & ENG & 0 & 12 & 25.3 & 48 & 14.7 & (1.00 & & \\
\hline During the recent decade new therapeutic & PL & 0 & 2.2 & 18.7 & 50 & 29.1 & & & \\
\hline $\begin{array}{l}\text { options have emerged for neurological } \\
\text { disorders }\end{array}$ & ENG & 1.3 & 0 & 29.4 & 40 & 29.3 & 6.94 & 4 & 0.14 \\
\hline Neurology deals with patients with emergen- & PL & 1.5 & 31.3 & 5.2 & 45.5 & 16.4 & 184 & 4 & 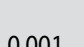 \\
\hline cy and lite-threatening conditions & ENG & 0 & 13.3 & 4 & 42.7 & 40 & 10.7 & $T$ & 0.001 \\
\hline Neurological disorders are usually chronic & $P L$ & 0 & 0 & 1.5 & 33.6 & 64.9 & & & \\
\hline $\begin{array}{l}\text { ones and they substantially affect the pa- } \\
\text { tients' quality of life }\end{array}$ & ENG & 0 & 1.3 & 4 & 50.7 & 44 & 10.3 & 3 & 0.017 \\
\hline Consequences of neurological disorders of- & PL & 0 & 6.7 & 5.3 & 53.7 & 37.3 & & & \\
\hline ten include disability and cognitive problems & ENG & 0 & 4 & 2.7 & 54.6 & 38.7 & $0.1 /$ & 3 & 0.80 \\
\hline Managing the patients with neurological & $P L$ & 0.8 & 6 & 2.2 & 47 & 44 & & & \\
\hline $\begin{array}{l}\text { diseases carries an emotional burden for the } \\
\text { physician }\end{array}$ & ENG & 2.7 & 14.7 & 24 & 38.7 & 20 & 36.5 & 4 & 0.0000 \\
\hline Patients with neurological diseases need & $P L$ & 0 & 4.5 & 3 & 43.3 & 49.3 & 287 & 3 & ח \\
\hline Interdisciplinary care & EN & 0 & 4 & 25.3 & 45.3 & 25.3 & 20.1 & & \\
\hline Nervous system can often be involved in the & $P L$ & 0 & 13.4 & 14.9 & 53 & 18.7 & 114 & 3 & \\
\hline course or alseases or otner organs/systems & ENG & 0 & 9.3 & 5.3 & 48 & 37.3 & ד. & J & (3) \\
\hline
\end{tabular}

$p=$ statistically significant

group influenced the final formulation of the questionnaire, the survey results did not exactly mirror the focus group opinion. Some meaningful differences between these findings justify the triangulation of data within a mixed methods approach.

\section{Attitudes towards neurology}

Approximately $80 \%$ of survey respondents regarded neurology as difficult, but also interesting and important for medical education. Nearly half of the students considered it relevant for their future speciality.
In the free text comments, the students valued neurology for its interesting content, variety of problems, constant progress, rationality, and providing opportunities for research. These were mostly consistent with the focus group findings, although its participants called neurology "logical" and "making progress" above all other descriptions, and emphasised its usefulness in other specialities.

Negative aspects of neurology described in the survey included: difficulties in learning (especially basic neurosciences), specificity of neurological disorders (chronic, 


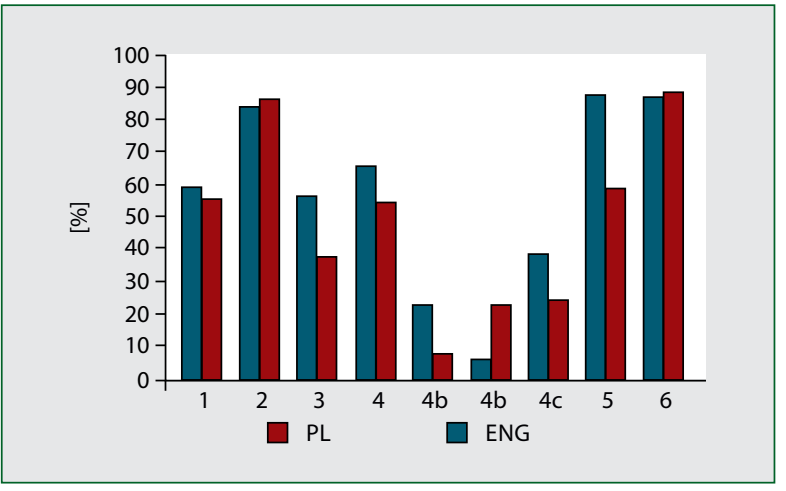

Figure 2. Percentage of respondents having experienced the following neurology-related issues: 1- neurological disorder among family or friends, 2 - meeting a patient with neurological disorder during other clinical classes, 3 - meeting a specialist in neurology; $\mathbf{4}$ - hearing opinion on neurology from an older student or physician ( $a$ - positive, $b$ - negative, c - neutral or not specified), 5 - learning about neurological problem from professional resources, $\mathbf{6}$ - learning about neurological problem from popular media, PL- Polish students, ENG - English-speaking student

progressive, disabling) and patients (communication problems), insufficient treatment options, and an emerging emotional burden. Focus group participants noticed similar drawbacks to neurology and paid attention to the disorders' impact upon cognition. Although not discouraged by learning the theoretical basis, they perceived the interpretation of neurological examination and the diagnostic process to be more difficult and challenging.

The survey findings showed the greatest proportion of uncertainty regarding the issues of the unknown background of the diseases and their incurability. This might suggest these topics were not adequately addressed during the course.

Unlike the focus group findings, the results from the survey showed that two-thirds of students found neurological examinations difficult, up to $30 \%$ doubted if neurology covered emergencies, and approximately $20 \%$ were uncertain about progress in therapies or the links between neurology and other specialities. These differences could indicate that the focus group participants were more interested in neurology and better recognised its specificity.

Overall, the study participants expressed a more positive approach to neurology than has been described in the literature. Negative attitudes have been consistently shown in the studies on 'neurophobia' $[3,10-16]$, with the majority of students finding neurology difficult, a moderate proportion displaying some interest in it $[11,13,16]$, and a minority admitting its importance for medical education [10]. However, specific drawbacks of neurology named in these studies are comparable with the findings of this study. Surprisingly, the unclear background of neurological disorders and insufficient treatment options had remained the main discouraging issues since the 1950s [17] or 1970s [7], a fact which brings into question the students' perception of progress in neurology.
Positive aspects of neurology (similar to those perceived by participants in our study) have been addressed in studies on speciality choices [8-21].

\section{Neurology as future speciality}

Approximately $18 \%$ of the survey respondents (both Polish and English-speaking) considered neurology for their future career, which ranked it within the five most popular specialities. Although only half of the students claimed they had definitely made their choice, such an interest in neurology seemed surprisingly high. The reasons for selecting neurology included the positive aspects discussed above. Those considering other specialities more often declared other preferences, rather than explicitly rejecting neurology.

A half of the focus group participants planned to become neurologists, so had a positive approach to the subject. Their discussion showed that they had a thorough insight into the specificity of neurology, and felt ready to manage its shortcomings.

The studies on 'neurophobia' have highlighted a low proportion of students planning a career in neurology [3, 11-13, $15,22]$. The results of an Indian survey [18] stand out from these, with almost one-third of undergraduates considering a choice of neurology, which might indicate some local context for its popularity. Polish research [7-8] showed a similarly low percentage of students choosing to specialise in neurology $(8 \%$ and 5.7\%) despite progress in neurology and evolution in the postgraduate training model which had occurred between the 1970s and 2000s.

The high popularity of neurology within the survey findings has to be interpreted cautiously, considering the response rate (i.e. those who did not respond were probably less interested) and the possible intention of respondents of making a positive impression on the neurology teachers.

\section{Factors affecting attitudes towards neurology}

\section{Gender}

Few significant gender differences were found in this study. Female participants in the focus group expressed their concern with work-life balance and possible gender discrimination during postgraduate training. More female respondents of the survey were convinced that neurological diagnostics is difficult. In a UK survey [12] women were less prone than men to choose a career in neurology, and Arabic female students [15] found neurological examination more difficult than males. Overall, gender did not seem to affect the students' perception of neurology in this study.

\section{Polish vs English-speaking students}

The survey findings provided some differences in attitudes towards neurology between Poles and non-Poles. The latter were more convinced that neurology was important for 


\section{The focus group questions:}

- what are your associations with neurology?

- in your opinion, what are the pros and cons of neurology?

- would you consider neurology as future career? Why/why not?

- what do you think the neurologist's job looks like?

- had you had any experiences linked with neurology before the medical studies or during early years?

- how do you perceive the course in neurology (programme, organizational issues, teaching)?

- have you changed your previous opinion on neurology and in which manner? what were the reasons for this change?

\section{The questionnaire}

Age:

Gender:

Country of origin:

Native language:

Please tick relevant option: Erasmus English Division

\section{Please tick ONE box which best corresponds with your view}

1. In comparison to the other clinical subjects, do you find neurology:

difficult?

interesting?

important part of general medical education?

relevant for your future specialty?

2. How much do you agree with the following statements:

\begin{tabular}{|c|c|c|c|c|c|}
\hline & Definitely not & Rather not & Don't know & Somewhat yes & Definitely yes \\
\hline \multicolumn{6}{|l|}{$\begin{array}{l}\text { learning neurology requires knowledge of difficult ana- } \\
\text { tomy and physiology of the nervous system }\end{array}$} \\
\hline \multicolumn{6}{|l|}{$\begin{array}{l}\text { neurosciences constitute an interesting and constantly } \\
\text { developing knowledge domain }\end{array}$} \\
\hline \multicolumn{6}{|l|}{$\begin{array}{l}\text { neurological examination is difficult to perform and } \\
\text { interpret }\end{array}$} \\
\hline \multicolumn{6}{|l|}{$\begin{array}{l}\text { diagnostics of neurological symptoms and signs is based } \\
\text { on rational and deductive thinking }\end{array}$} \\
\hline \multicolumn{6}{|l|}{$\begin{array}{l}\text { variety of up-to-date diagnostics methods are used in } \\
\text { neurology }\end{array}$} \\
\hline \multicolumn{6}{|l|}{$\begin{array}{l}\text { diagnosis of neurological disorders is often difficult and } \\
\text { challenging }\end{array}$} \\
\hline \multicolumn{6}{|l|}{$\begin{array}{l}\text { the background of neurological diseases often remains } \\
\text { unknown }\end{array}$} \\
\hline \multicolumn{6}{|l|}{ neurological diseases are mostly incurable } \\
\hline \multicolumn{6}{|l|}{$\begin{array}{l}\text { during the recent decade new therapeutic options have } \\
\text { emerged for neurological disorders }\end{array}$} \\
\hline & Definitely not & Rather not & Don't know & Somewhat yes & Definitely yes \\
\hline \multicolumn{6}{|l|}{$\begin{array}{l}\text { neurology deals with patients with emergency and life- } \\
\text {-threatening conditions }\end{array}$} \\
\hline \multicolumn{6}{|l|}{$\begin{array}{l}\text { neurological disorders are usually chronic ones and they } \\
\text { substantially affect the patients' quality of life }\end{array}$} \\
\hline \multicolumn{6}{|l|}{$\begin{array}{l}\text { consequences of neurological disorders often include } \\
\text { disability and cognitive problems }\end{array}$} \\
\hline \multicolumn{6}{|l|}{$\begin{array}{l}\text { managing the patients with neurological diseases carry } \\
\text { an emotional burden for the physician }\end{array}$} \\
\hline \multicolumn{6}{|l|}{$\begin{array}{l}\text { patients with neurological diseases need interdiscipli- } \\
\text { nary care }\end{array}$} \\
\hline $\begin{array}{l}\text { nervous system can be often involved in the course of } \\
\text { diseases of other organs/systems }\end{array}$ & & & & & \\
\hline
\end{tabular}


3. Please list up to three specialties you consider to choose for your career

Please explain briefly why you would or would not choose neurology

If you have already chosen your future specialty, when did you make this choice?

Please tick one of the boxes: YES or NO

4. Before attending the course in neurology, have you ever:

YES NO

had any personal experience with neurological disease (among family, friends etc.)?

met patients with neurological disease during other clinical classes?

met a specialist in neurology or a physician during such specialization?

heard some opinion on neurology from senior students or residents/physicians of other specialties?

If YES, was it positive or negative one?

learnt about any problem in the field of neurology or neurosciences from medical/professional resources (textbook, journal etc.)?

learnt about any neurological disorder from popular literature or media (movies, TV series, radio, website etc.)?

5. Please name 1-3 positive aspects

and 1-3 negative aspects

of the course in neurology you are currently attending.

Please tick ONE box which best corresponds with your view

6. Do you think the timing/schedule of neurology course is appropriate:

definitely not rather not don't know somewhatyes definitely yes

two terms during the 5 th year

duration of mandatory blocks in each term (8)

structure of single classes ( $1 \mathrm{~h}$ seminar, $2 \mathrm{~h}$ bedside classes)

form of exam (verbal, theoretical)

If "rather not" or "definitely not", what would you change?

7. Have you found the following forms of teaching helpful during course in neurology:

definitely not rather not don't know somewhatyes definitely yes

seminars/tutorials

bedside classes:

- taking history

- neurological examination

- diagnostic tests review

- case-based discussions

- lectures/presentations 
8. Was your teacher(s) attitude supportive in learning neurology?

$\begin{array}{ccccc}\text { definitely not } & \text { rather not } & \text { don't know } & \text { somewhat yes } & \text { definitely yes } \\ \square & \square & \square & \square & \square \\ \text { rather not } & \text { don't know } & \text { somewhat yes } & \text { definitely yes } & \\ \square & \square & \square & \square & \square \\ \square & \square & \square & \square & \square\end{array}$

9. Have you changed your previous opinion about neurology not

- during/after the course?

- influenced by the teacher?

If "somewhat yes" or "definitely yes" please explain briefly

10. Which methods of learning do you use with regard to neurology?

\begin{tabular}{|c|c|c|c|c|c|}
\hline textbooks & $\begin{array}{c}\text { definitely not } \\
\square\end{array}$ & $\begin{array}{c}\text { rather not } \\
\square\end{array}$ & $\begin{array}{c}\text { don't know } \\
\square\end{array}$ & $\begin{array}{c}\text { somewhat yes } \\
\square\end{array}$ & $\begin{array}{c}\text { definitely yes } \\
\square\end{array}$ \\
\hline revision of notes made during the classes & $\square$ & $\square$ & $\square$ & $\square$ & $\square$ \\
\hline own notes (schemes, mind maps etc) & $\square$ & $\square$ & $\square$ & $\square$ & $\square$ \\
\hline tests & $\square$ & $\square$ & $\square$ & $\square$ & $\square$ \\
\hline online resources & $\square$ & $\square$ & $\square$ & $\square$ & $\square$ \\
\hline group learning & $\square$ & $\square$ & $\square$ & $\square$ & $\square$ \\
\hline
\end{tabular}

Please give examples of online resources if you use any

Any other resources? Please specify

11. Do you feel confident with the material you have learnt so far during the course in neurology

definitely not rather not

don't know somewhat yes definitely yes

theoretical knowledge

practical skills

Please tick ONE of the boxes: YES or NO

12. Have you undertaken (or are going to) any additional learning activity in neurology

$\begin{array}{lcc} & \text { YES } & \text { NO } \\ \text { meetings of Students' Scientific Club } & \square & \square \\ \text { assisting the specialist/teacher during consultations } & \square & \square \\ \text { Any other? please specify } & & \end{array}$

If YES please explain briefly the reason for choosing these activities

If NO please suggest if any form of additional learning in neurology would attract your attention

Thank you for the completion of the questionnaire. 
medical education, covered emergency conditions, had interdisciplinary links and could be associated with an emotional burden. Polish students were more convinced that neurological disorders are chronic and often have an unknown background, and that modern diagnostic methods are available in neurology. However, a large proportion of both subgroups regarded neurology as interesting as well as difficult.

Although neurology was equally popular among Poles and non-Poles as a future speciality, some differences were noted in their motivation, probably conditioned by the cultures within particular countries. Polish students felt discouraged by the limited availability of residency posts, few opportunities for interesting jobs, and limited practical applicability of knowledge. On the other hand, non-Poles perceived neurology to be an interesting professional career as an expert in a narrow speciality.

The review of literature from various countries revealed similar perspectives on 'neurophobic' attitudes, and limited interest in a neurology career. However, the distinct findings from the UK [12] and Indian surveys [18], in which neurology was middle-ranked or high-ranked as a future speciality, may indicate the role of cultural and socio-economic background in shaping the students' approach.

\section{Experiences preceding neurology course}

The majority of the survey respondents had faced earlier neurology-related experiences. More than $80 \%$ had met patients with neurological disorders during other clinical courses and learnt about neurological problems from professional resources or popular media. More than $50 \%$ had heard some opinion on neurology and had encountered a neurological disorder among family or friends. The focus group participants mentioned similar experiences.

English-speaking respondents had more often met a neurologist, heard more positive than negative opinions on neurology, and used more professional resources.

These experiences did not seem to affect substantially the undergraduates' perception of neurology. Those focus group participants who planned to become neurologists were usually driven by an interest in neurosciences developed during preclinical years, had studied neurological problems on their own, and did not feel discouraged by negative opinions of this speciality.

These findings appear to contradict those from the UK and USA $[12,20]$, which revealed the impact of personal experiences upon an interest in neurology and its choice as a future career. Canadian authors [10] highlighted the role of 'preconceptions' in shaping negative attitudes towards neurology. Their findings showed that the most daunting experiences included contacts with patients with neurological disorders (without relevant knowledge about them), negative opinions of other specialists, and an unfavourable image of neurologists.

\section{The course in neurology}

Unlike previous experiences, the course in neurology did contribute to the students' perception of neurology. The focus group participants claimed the course was a valuable source of knowledge and allowed them to verify their idea of the speciality. More than $40 \%$ of the survey respondents changed their previous opinion on neurology, usually for the better. This change was caused by a deeper understanding of neurological issues and their relevance, and also by effective and supportive teaching. Sporadic contrary experiences included disappointment with the content of the course or with a poor teacher's performance.

Both these aspects are addressed in the literature. Many studies [10, 18-20, 23-24] have highlighted the potential of positive training experiences to overcome prejudices against neurology, improve its image, and encourage speciality choice. However, some authors $[10,15,20]$ have indicated that negative experiences from the course might become the dominant reason for an adverse attitude towards neurology.

\section{Implications and future directions}

The strength of this study is its presentation of a range of attitudes towards neurology and perception of its various aspects within a representative group of undergraduates.

The limitations of this study include its local character (little possibility of generalisation) and lack of an English-speaking focus group (due to expected problems emerging from the language barrier). The findings from the survey might have been biased by its having been conducted just before the exam session. Despite efforts to limit pressures arising from the teacher-student relationship, some students might have refrained from expressing critical remarks, or responding to the survey. Addressing the survey to sixth year students or conducting it online might eliminate this bias, but presumably at the cost of a lower response rate.

Continuing studies within this field might involve further exploration of the students' perception of neurosciences, with regard to teaching and learning aspects. Their perspective might be evaluated during preclinical years and comparatively towards the end of their studies, to follow its dynamics. Other factors, including the socioeconomic status of the students and their migration plans, might be considered. Online surveys might be addressed to undergraduates from other medical faculties in Poland to compare the local findings with their opinions. The students' perspective might also be supplemented by the teachers' point of view.

\section{Conclusions}

Fifth year medical undergraduates expressed mostly positive attitudes towards neurology, perceived by the majority to be interesting and important for medical education, and it ranked highly as a prospective future speciality. However, 
the majority of the survey participants regarded neurology as difficult and noticed specific drawbacks of this speciality.

In spite of a similar general perception of neurology, Polish and English-speaking students differed in their perception of particular aspects. This was conditioned by diversity in cultural background and earlier experiences associated with neurology.

The course in neurology affected attitudes towards the subject more than preceding experiences, mostly in a positive manner. This is an important message for clinical teachers and would be worth pursuing in other specialities. The feedback from undergraduates may contribute to improvements in the teaching of neurology, especially with regards to less frequently considered topics and the integration of neurology with other subjects.

Sources of funding / conflict of interests: This article constitutes part of a dissertation for an MSc degree in Clinical Education at the University of Edinburgh. Attending the Clinical Education programme by Anna Pokryszko-Dragan was supported by a Polish School of Medicine Memorial Fund scholarship. Gill Aitken is the Director of the Clinical Education programme, and together with John Mottershead she supervised the dissertation. No conflict of interest existed for any of the authors.

\section{References}

1. Neurological Disorders: Public Health Challenges. Neurol Disord Public Heal Challenges. 2006: 41-176, doi: 10.1001/archneurol.2007.19.

2. Jozefowicz RF. Neurophobia: the fear of neurology among medical students. Arch Neurol. 1994; 51(4): 328-329, indexed in Pubmed: 8155008.

3. Zinchuk A, Flanagan E, Tubridy N, et al. Attitudes of US medical trainees towards neurology education: "Neurophobia" - a global issue. BMC Medical Education. 2010; 10(1), doi: 10.1186/14726920-10-49.

4. Solorzano GE, Józefowicz RF. Neurophobia: a chronic disease of medical students. Neurology. 2015; 85(2): 116-117, doi: 10.1212/ WNL.0000000000001751, indexed in Pubmed: 26070337.

5. McGee J, Maghzi AH, Minagar A. Neurophobia: a global and under-recognized phenomenon. Clin Neurol Neurosurg. 2014; 122: iii-iv, doi: 10.1016/j.clineuro.2014.03.023, indexed in Pubmed: 24726892.

6. Nicholl DJ, Appleton JP. Clinical neurology: why this still matters in the 21st century. J Neurol Neurosurg Psychiatry. 2015; 86(2): 229-233, doi: 10.1136/jnnp-2013-306881, indexed in Pubmed: 24879832.

7. Zieliński JJ, Bejnarowicz J, Drabrowska-Kaczmarek A, et al. [Place and role of clinical neurology in the opinion of students graduating from medical schools]. Neurol Neurochir Pol. 1979; 13(4): 411-416, indexed in Pubmed: 481693.
8. Trzeciak B, Siebert J, Kliszcz J, et al. Specialties' preferences of students of Medical University in Gdansk during the transformation period. Fam Med Prim Care Rev. 2006; 8: 77-81.

9. Ministry Health. http://www mz gov pl/system-ochrony-zdrowia/kadra-medyczna.

10. Fantaneanu TA, Moreau K, Eady K, et al. Neurophobia inception: a study of trainees' perceptions of neurology education. Can J Neurol Sci. 2014; 41(4): 421-429, indexed in Pubmed: 24878464.

11. Youssef FF. Neurophobia and its implications: evidence from a Caribbean medical school. BMC Med Educ. 2009; 9: 39, doi: 10.1186/14726920-9-39, indexed in Pubmed: 19570231.

12. Pakpoor J, Handel AE, Disanto G, et al. Association of British Neurologists. National survey of UK medical students on the perception of neurology. BMC Med Educ. 2014; 14: 225-229, doi: 10.1186/14726920-14-225, indexed in Pubmed: 25335431.

13. Matthias AT, Nagasingha $P$, Ranasinghe $P$, et al. Neurophobia among medical students and non-specialist doctors in Sri Lanka. BMC Med Educ. 2013; 13: 164, doi: 10.1186/1472-6920-13-164, indexed in Pubmed: 24321477.

14. Flanagan E, Walsh C, Tubridy N. ?Neurophobia?? attitudes of medical students and doctors in Ireland to neurological teaching. European Journal of Neurology. 2007; 14(10): 1109-1112, doi: 10.1111/j.1468-1331.2007.01911.x.

15. Lukas R, Albert D, Abulaban A, et al. Neurophobia among medical students. Neurosciences. 2015; 20(4): 404-404, doi: 10.17712/ nsj.2015.4.20150500.

16. Schon F. Is clinical neurology really so difficult? Journal of Neurology, Neurosurgery \& Psychiatry. 2002; 72(5): 557-559, doi: 10.1136/ jnnp.72.5.557.

17. POSER CM. Undergraduate attitudes toward the specialty of neurology. Neurology. 1959; 9: 682-688, indexed in Pubmed: 14434363.

18. Khadilkar S, Bangar S, Patil T, et al. Neurology as career option among postgraduate medical students. Annals of Indian Academy of Neurology. 2013; 16(4): 478-482, doi: 10.4103/0972-2327.120427.

19. Albert D, Hoyle C, Yin $\mathrm{H}$, et al. Why neurology? Factors which influence career choice in neurology. Neurological Research. 2016; 38(1): 10-14, doi: 10.1080/01616412.2015.1120444.

20. Kamour A, Han D, Mannino D, et al. Factors that impact medical student and house-staff career interest in brain related specialties. Journal of the Neurological Sciences. 2016; 369: 312-317, doi: 10.1016/j.jns.2016.08.046.

21. Humbert K, Chang B. In the beginning: How medical students choose (or do not choose) neurology. Annals of Neurology. 2014; 75(4): 487-489, doi: 10.1002/ana.24133.

22. Ridsdale L, Massey R, Clark L. Preventing neurophobia in medical students, and so future doctors. Pract Neurol. 2007; 7(2): 116-123, indexed in Pubmed: 17430877.

23. Fuller G. Neurophilia: a fascination for neurology-a new syndrome. Practical Neurology. 2012; 12(5): 276-278, doi: 10.1136/practneurol-2012-000400.

24. Giles J. Clinical neuroscience attachments: a student's view of 'neurophobia'. Clin Teach. 2010; 7(1): 9-13, doi: 10.1111/j.1743-498X.2009.00330.x, indexed in Pubmed: 21134136. 